\title{
INVITACIÓN A REPENSAR LA CULTURA MATERIAL DE LA ESCUELA
}

\author{
Agustín Escolano Benito ${ }^{1}$ \\ Centro Internacional de la Cultura Escolar - CEINCE \\ ceince@ceince.eu
}

\begin{abstract}
RESUMEN
El ensayo plantea la necesidad de revisar la producción académica acumulada en las últimas décadas acerca de la denominada cultura material de la escuela en orden a dotar a la nueva línea historiográfica de un mayor rigor epistémico e intelectual que trascienda los habituales enfoques etnográficos de la historia de las prácticas formativas. Legitimando lo matérico como fuente de la cultura empírica de la escuela y del habitus artesanal de la profesión docente, el presente trabajo trata de fundar una historiografía más sincera y realista que combine la etnohistoria con la hermenéutica bajo un enfoque antropológico, a la vez que pluritópico, que de acceso al esclarecimiento de los discursos subyacentes en las experiencias relativas a la formación humana y a su códigos de sociabilidad.
\end{abstract}

Palabras clave: Cultura material de la escuela. Patrimonio histórico educativo. Episteme de la cultura empírica de la formación. Etnohistoria y hermenéutica. Prácticas y discursos en educación.

\section{CONVITE PARA REPENSAR A CULTURA MATERIAL DA ESCOLA}

\section{RESUMO}

O ensaio suscita a necessidade de rever a produção acadêmica acumulada nas últimas décadas sobre a denominada cultura material da escola, a fim de dotar a nova linha historiográfica de um maior rigor epistêmico e intelectual que transcenda os enfoques etnográficos habituais da história das práticas formativas. Legitimando o material como fonte da cultura empírica da escola e do habitus artesão da profissão docente, o presente trabalho busca fundar uma historiografia mais sincera e realista que combine a etno-história com a hermenêutica sob um enfoque antropológico, bem como pluri-tópico, que dê acesso ao esclarecimento dos discursos subjacentes nas experiências associadas à formação humana e aos seus códigos de sociabilidade.

Palavras-chave: Cultura material da escola. Patrimônio histórico-educativo. Episteme da cultura empírica da formação. Etno-história e hermenêutica. Práticas e discursos em educação.

\section{INVITATION TO RE-THINK SCHOOL MATERIAL CULTURE}

\begin{abstract}
\footnotetext{
1 Catedrático de Historia de la Educación de la Universidad de Valladolid y fundador-director del Centro Internacional de la Cultura Escolar (CEINCE) con sede en Berlanga de Duero, España. Es doctor honoris causa por la Universidad de Lisboa, Premio Nacional Manuel Bartolomé Cossío y doctor honorario del Colegio de
} Doctores de Salamanca.
\end{abstract}


The essay raises the necessity to revise the accumulated academic production over the past few decades about the denominated material culture of the school in order to endow new historiographical approach greater epistemic and intellectual rigor that transcends the ethnographic prospects of the history of formative practices. Legitimizing the material as a source of the school's empirical culture and of the teaching profession's artisan habitus, the present work aims a more sincere and realistic historiography that combines ethnohistory with hermeneutics under an anthropological angle, at the same time as plurithopic, that gives access to the clarification of the discourses underlying the experiences related to human formation and its codes of sociability.

Keywords: School material culture. Historical educational heritage. Episteme of the empirical culture of training. Ethnohistory and hermeneutics. Practices and discourses in educacion.

\section{INVITATION À REPENSER LA CULTURE MATÉRIELLE DE L'ÉCOLE}

\section{RÉSUMÉ}

Cet essai soulève la nécessité de réviser la production académique accumulée au cours des dernières décennies sur le dit culture matériel de l'école pour équiper la nouvelle ligne historiographie d'une plus grande rigueur épistémique et intellectuelle qui aille au-delà des approches ethnographiques habituelles de l'histoire de pratiques formatives. En légitimant dans le matériel comme source de la culture empirique de l'école et de l'habitus artisanal de la profession enseignant, cet essaie tente de fonder une historiographie plus sincère et réaliste qui allie l'ethnohistoire avec 1' herméneutique sous une approche anthropologique, ainsi que pluritopique, qui donne accès à la clarification des discours sous-jacents dans les expériences liées à la formation humaine et à ses codes de sociabilité.

Mots-clés: Culture matérielle de l'école. Patrimoine historique éducatif. Épistémè de la culture empirique de la formation. Ethnohistoire et herméneutique. Pratiques et discours en éducation.

\section{HISTORIA INTELECTUAL DE LO MATERIAL}

Este texto propone algunas y reflexiones y sugerencias en orden a responder a la necesidad de repensar la cultura material de la escuela, un campo que se ha ido abriendo y configurando en los últimos años como una corriente historiográfica innovadora y dominante en la nueva historia intelectual de la educación. Fue esta sin duda una cuestión que estuvo sobre la mesa en todas las sesiones de trabajo del Simposio Internacional sobre el Patrimonio Histórico Educativo organizado por la red RIDPHE en la sede del CEINCE en julio de 2019.

Material e intelectual - conviene advertirlo en la entrada - no se contraponen, como pudiera a primera vista sospecharse, toda vez que la consideración de las materialidades como objeto y como contenidos por parte de la historiografía contemporánea, y no solo como fuente, obedece a una operación de la historia cultural que se ha de llevar a cabo desde presupuestos intelectuales. De no ser así, la operación histórica se reduciría a ser una mera construcción 
etnográfica, y por consiguiente no trascendería la orientación positivista e instrumental del análisis.

Algunos debates suscitados en la propia comunidad académica de historiadores de la educación vienen sugiriendo la necesidad de interpretar con más rigor crítico el alcance y sentido que puede tener este tipo de cultura escolar que se define a sí misma como material. Además, nuestras reflexiones reconocen que no solo es la academia sino toda la sociedad la que apoya la operación de reconstruir el patrimonio histórico de la educación, el material y el inmaterial, por considerar que este acervo es un elemento cultural, de fuertes valencias formativas, que ha de ser asumido en una sociedad ilustrada y democrática como un bien común. Por ello justamente, los contenidos de esta cultura han entrado ya a formar parte, a través principalmente de los programas museográficos y de las investigaciones acerca de la memoria histórica, de los espacios públicos que las comunidades ofrecen para su conservación, estudio y disfrute, así como de los proyectos de formación de los profesionales de la educación y de toda la ciudadanía.

Este ensayo llama la atención al tiempo sobre una cuestión que no ha sido a nuestro entender suficientemente ponderada, a saber: que el interés por lo material como hecho de cultura no es tan nuevo como pudiera parecer, aunque hoy se pueda percibir como una preocupación más motivada y mejor documentada, por los registros de mayor visibilidad que se construyen en la actualidad. Nuestro tiempo, apoyado en los potentes visores que proporcionan las nuevas tecnologías, y por lógica de la llamada cultura simulacro — atenta a menudo más a las representaciones que a las voluntades o intenciones-, se ha hecho sin duda más performativo, pero a la vez ha trivializado y simplificado algunos análisis y tratamientos acerca de los objetos y las imágenes. No obstante lo anterior, no conviene olvidar que ya el clásico materialismo histórico y las filosofías posestructurales destacaron el poder de lo material como fuerza transformadora de la realidad, así como el interés hermenéutico de la dimensión semántica depositada, como cultura implícita, en las cosas. En las últimas décadas, la sociología cultural también ha revalorizado el ámbito de lo material, sin caer en ejercicios neopositivistas o en el espontaneísmo etnográfico. No es nuevo pues el reclamo de lo material como testimonio de una cultura y como estímulo para la reflexión intelectual acerca de ella.

Hace ahora un decenio, la Sociedad Española del Patrimonio Histórico Educativo organizó en la misma sede del CEINCE unas jornadas nacionales intituladas "La Cultura Material de la Escuela", en las que participaron representantes de la mayor parte de las regiones 
del país que habían puesto en marcha experiencias museográficas ${ }^{2}$. En el corto tiempo transcurrido desde entonces nuestro entorno se ha poblado de museos y centros de memoria, reales y virtuales, relacionados con la escuela y la educación. En otros medios ha sucedido algo parecido. También se han promovido museos, redes, publicaciones periódicas, series editoriales, eventos académicos y otros dispositivos de transmisión e intercambio de la experiencia. Estas iniciativas han generado conocimientos que han implementado y reforzado el interés por las materialidades.

Probablemente estamos acercándonos — piensan algunos observadores - a cubrir las expectativas de la fase acumulativa de los recursos físicos que configuran el archivo de la historia material de la formación, o hemos logrado reunir al menos un elenco suficientemente representativo del conjunto deseable para poder apoyar con eficiencia la construcción de esta modalidad de cultura. El crecimiento de los contenidos que pueblan las colecciones y los museos, o los reservorios virtuales, no se ha visto acompañado sin embargo del aconsejable nivel de reflexividad sobre la significación y el sentido de los legados reunidos. Tampoco se ha procedido a la evaluación de los efectos sociales y culturales de estos medios materiales en las comunidades que los acumulan y difunden.

Más allá de lo anterior es preciso invitar a repensar los significados y el valor que ha de atribuirse, en nuestro tiempo y en el próximo futuro, a las materialidades de la escuela, esto es, a las cosas que hemos recibido como herencia tangible del pasado de la educación, trascendiendo el evidente papel etnográfico, lúdico y formativo que desempeñan los objetos y las representaciones icónicas y narrativas en las colectividades en las que se ha llevado a cabo el proceso de escolarización de los menores y de los jóvenes que han formado parte del tejido social. Igualmente quiere ayudar a interpretar la función que cumplen estas prácticas de memoria en la construcción de las identidades personales y colectivas y en la conformación de la cultura empírica de la educación, tema al que hemos dedicado hace poco otra publicación ${ }^{3}$. Esta perspectiva nos aboca ya de modo expreso a considerar la historia material como historia intelectual.

\section{MATERIALIDADES Y EXPERIENCIA}

\footnotetext{
${ }^{2}$ Véase: Agustín Escolano Benito (ed.), La cultura material de la escuela, Berlanga de Duero, CEINCE, 2007. ${ }^{3}$ Agustín Escolano Benito, La cultura empírica della scuolo. Esperienza, memoria, archeologia, Ferrara, Volta la Carta, 2016.
} 
En los epígrafes que siguen se exploran las vías intelectuales que se han ensayado en el pasado próximo a nosotros para poner en valor los testimonios matéricos como fuentes de la cultura empírica de la educación. Bajo esta intención, queremos mostrar que la cultura material asociada a la historia de los procesos de la formación humana no es solo el resultado de una curiosidad etnológica sino una mediación intelectual que se construye y se comunica por necesidad hermenéutica. No es pues esta cultura un complemento ilustrativo de otros tipos de reconstrucción del pasado, sino la prueba testimonial que da acceso a la comprensión efectiva de la historia escolar.

La historia material es un vector esencial de toda historia de la experiencia, en educación y en otros muchos sectores de la vida cotidiana. También lo es de las ciencias humanas que se ocupan de explicar e interpretar algún ámbito del mundo experiencial. No existe una historia de la experiencia que no se sustente en los hechos materiales vinculados a ella. El retorno a la empeiria supone en cierto modo una especie de giro, de signo aristotélico, que trata de corregir las desviaciones racionalistas e ideológicas que han dominado hasta ahora en los saberes acerca de la educación, incluida la historia. Busca asimismo tratar de entender las relaciones que los sujetos entablan con las cosas en los contextos en los que se llevan a cabo las acciones prácticas de la formación.

En otro lugar hemos glosado con suficiente extensión el relato de ficción titulado $E l$ testamento de Aristóteles, obra en la que su autor, Alfredo Marcos, pone en boca del sabio de Estagira la epístola que este dirige a su discípulo y albacea Antípatro, en la que relata elementos de la memoria de su propia experiencia formativa en la infancia y da cuenta del utillaje habitual de las escuelas de su tiempo. El mismo Aristóteles y los niños de la época — se puede leer en esta carta - "cargaban su tierna anatomía -ayudados por sus esclavos (los pedagogos) - con tablillas, punzones, trozos de tinta, tinteros, cítaras, horrísonas flautas, reglas para alinear las letras, libros de Homero y otros poetas, rollos de papiro, cálamos, ábaco, esponja y espátula"4. De este ajuar instrumental que relata el anterior inventario se servirían los niños y los maestros de la Grecia clásica. El escrito alude asimismo a algunas de las prácticas que se llevaban a cabo con estos objetos, con lo que la historia material de la escuela se vincula en el relato a la historia de los métodos, e incluso se abre a la consideración de las habilidades que el manejo de los objetos requería, como en el caso de la escritura, y a la educación de los sentimientos que en algunos sectores, como el relativo a la música, estimulaba. He aquí pues un ejemplo del significado y valor que puede adquirir la historia de la cultura material para comprender los

\footnotetext{
${ }^{4}$ Alfredo Marcos, El testamento de Aristóteles. Memorias desde el exilio, León, EDILESA, 2000, p. 123-124.
} 
procesos formativos que promovía la pragmática escolar en el mundo antiguo, más allá del elemental interés etnográfico que puede tener estas fuentes.

Objetos parecidos a los que formaron parte del utillaje de la escuela en tiempos de Aristóteles, e incluso de épocas anteriores, se siguieron empleando en instituciones de tiempos más modernos. Durante siglos, la escuela se ha servido de tablillas, pizarras, ábacos y otros objetos para apoyar los métodos de enseñanza. La materia de que están hechos ha variado de acuerdo a la evolución de la civilización y de las tecnologías, pero el formato y la funcionalidad se ha mantenido en lo básico. Una tableta de hoy mantiene ciertas semejanzas de medida y estructura con la vieja pizarra individual. Y los ábacos de nuestra época, aunque sean de mesa o virtuales, todavía conservan la vetusta estructura de líneas y bolas que tuvieron los primeros. Parece pues que algunos hallazgos técnicos arcaicos acertaron hace muchos siglos en la definición formal de un algoritmo material, el que sirve de modelo al ábaco, y ello puede tener algún significado cultural que ha quedado adherido a la fisicalidad de estos conocidos objetos.

Veamos otro tema relativo a la cultura material, también extraído del mundo clásico, que reenvía igualmente a la historia de los modos y métodos de aprendizaje: el que Martyn Lyons relata en su reciente historia de la lectura y escritura. Me refiero al capítulo de esta obra en el que el autor examina los cambios culturales — también pedagógicos - que derivaron de una innovación material y técnica: la sustitución del papiro por el pergamino en las prácticas de escribir/leer, mudanza que empezó a operarse en el siglo I de nuestra era. Todos sabemos el porqué de esta innovación: la mayor resistencia de la piel de animal sobre la hoja de papiro, de origen vegetal, y la adquisición del producto en el mercado próximo, así como la posibilidad de usarse el nuevo soporte matérico en sucesivas ocasiones, hecho que daría origen al palimpsesto. Como es sabido, la innovación material supuso el cambio del rollo al codex y ello afectó a las prácticas de escritura, y consiguientemente de lectura, incluidas las relacionadas con su enseñanza y aprendizaje, como mostraron ya hace tiempo diversos trabajos de Roger Chartier. En el rollo, el texto se disponía bajo la forma de scriptio continua, sin saltos de página, ni capítulos, ni índices. No era fácil seguir un texto ni orientarse en él. El papiro, que podía alcanzar varios metros de largo, era muy difícil de manejar. El códice en cambio adoptó la forma de libro, un modelo que ha llegado así, en soporte papel, hasta nuestros días. Su estructura paginada promovía otras prácticas lecto-escribanas. No necesitaba sostenerse con las dos manos, lo que liberaba una de ellas para poder leer, anotar, subrayar y realizar otras acciones 5 .

\footnotetext{
${ }^{5}$ Martyn Lyons, Historia de la lectura y de la escritura en el mundo occidental, Buenos Aires, Editoras del Calderón, 2012, p. 51-53.
} 
El cambio material, extendido en cuanto a utilización a partir de los primeros siglos de nuestra era, había propiciado pues importantes innovaciones en la escritura, así como en los métodos de aprender y enseñar a leer y a escribir y en la misma organización de las escuelas y de las bibliotecas. Una nueva cultura de la escuela estaba incoada pues en el cambio tecnológico que supuso el paso del rollo al codex. Más aún, tal giro no solo afectó a los modos o procedimientos didácticos, sino también a las nuevas formas de sociabilidad entre los actores que escribían, a las estructuras usadas para organizar los acervos de la memoria escrita (libros, páginas, índices, notas, citas) y hasta a las prácticas de guardar y difundir el patrimonio cultural que se archivaba en los nuevos dispositivos.

Un nuevo cambio se opera ahora, en relación con estas prácticas, con la aparición y uso de los procesadores de textos que ofrece el giro digital. El texto en pantalla recupera el modelo de rollo que hemos de leer - y también de escribir — de arriba abajo, y no de modo horizontal, como se hacía al principio en la escritura en papiro. La versatilidad de las nuevas tecnologías de información/comunicación permite asimismo recoger algunas de las aportaciones del codex, como las relativas a la paginación e indexación, al tiempo que facilita incorporar otras nuevas como las relacionadas con el almacenamiento, la recuperación de textos y la conectividad. Una nueva pragmática de la escuela deriva por tanto de los cambios materiales que suscita el giro tecnológico. Los historiadores del futuro podrán examinar estos cambios y sus consecuencias en los procesos de formación. Y nosotros, los historiadores del tiempo presente, podemos jugar con los futuros incoados en la tecnología actual, así como hacer observar los impactos que las nuevas materialidades proyectan sobre el mundo de la educación, junto a las persistencias del pasado. Tales juegos interpretativos suscitan hoy un análisis intelectual con sentido hermenéutico que ha de pivotar sobre la dialéctica existente entre la innovación y la tradición, entre el patrimonio y lo emergente. Todo ello se ha de hacer necesariamente tomando como fuentes de conocimiento los elementos materiales de las dos culturas tecnológicas que en la actualidad conviven en la escuela en régimen de cohabitación e interacción.

He aquí pues algunos ejemplos inteligibles que ponen de manifiesto la interconexión de la historia material con la historia de la experiencia, y que evidencian cómo a partir de los testimonios escolares primarios - las materialidades observables y manejables - se puede acceder a reconstruir una historia cultural de la educación mucho más compleja y pragmática, como la que corresponde a los métodos de aprender, a los modos de enseñar, a la comprensión de los sujetos implícitos en los textos y de las formas de sociabilidad que se dan entre ellos, así como a otros aspectos de los procesos formativos que están implícitos en la relación de los hombres y las mismas cosas, una relación que siempre es cultural. 


\section{LAS COSAS, DEL SILENCIO A SU LECTURA}

Las cosas no siempre hablan directamente a sus observadores, manipuladores o lectores, como sucede de forma evidente en los ejemplos antes comentados. Con frecuencia, según sugiere Jorge Luis Borges, los objetos son materialidades ciegas y sigilosas, aunque puedan guardar ciertos secretos de la cultura que albergan, claves que es necesario y posible desvelar a través de determinadas lecturas sugeridas por los indicios y las huellas observables. Estas lecturas de lo real — si son compartidas o debatidas, mejor — nos permitirán encontrar, bajo la simplicidad de las apariencias que muestran las cosas, el discurso que portan los materiales y las representaciones, un relato que afecta a la comprensión de la historia de las prácticas culturales y a la constitución de los saberes sobre la educación que han tratado de explicar la escuela como hecho de cultura.

Las cosas, por otra parte, pueden durar más allá del uso que hagamos de ellas, e incluso sobrepasar nuestra existencia en el tiempo, y hasta entrar a formar parte de la indefinida región de los olvidos, sin darse cuenta tampoco de que sus creadores y usuarios se han ido. Así, cargadas de la historicidad oculta que el transcurrir del tiempo les otorga, las materialidades se aplican a ulteriores usos y transformaciones, instituyendo como conjunto un legado, al que atribuimos el valor de patrimonio colectivo, que es aconsejable salvaguardar, investigar y difundir. Siguiendo este proceso, las cosas van pasando a constituirse en positividades o fuentes reificadas de conocimiento sobre las que los estudiosos definen lo que se ha dado en denominar la cultura material, presente en todas las esferas de la vida, y por supuesto también en la referida a la cultura de la escuela.

Los historiadores sospechan desde hace algún tiempo que los objetos y los iconos están dotados de códigos de los que el sujeto que los observa y manipula no tiene siempre conciencia, pero que tras su exhumación, y mediante los oportunos análisis semióticos, es posible hacerles salir de su silencio. Las cosas que forman parte del legado recibido, como hizo observar Freeman Tilden, uno de los primeros teóricos del patrimonio, no solo nos instruyen; también nos provocan para construir interpretaciones inteligentes, al igual que sucede en general en el mundo de las artes y de los documentos históricos. Los arqueólogos tratan de desvelar los significados que se ocultan detrás de lo que encuentran en sus búsquedas y de lo que perciben con los sentidos. Todo buen maestro - decía Tilden — puede ser sin duda un buen intérprete. Observar el corte de un árbol viejo y asociar los anillos que marcan el proceso de su crecimiento con la vida de la planta y relacionarlos a la vez con los ciclos temporales de la historia humana 
fue un logro de esta capacidad hermenéutica de un buen arqueólogo ${ }^{6}$. He aquí también una imagen del educador como intelectual.

\section{ARQUEOLOGÍA Y HERMENÉUTICA}

El interés por las cosas como objeto de cultura hay que retrotraerlo seguramente a Michel Foucault, el primer teórico que habló de la arqueología del saber al referirse a las ciencias humanas. Las formaciones discursivas en las que había de fundarse la historia de las ciencias, a partir de la primera modernidad (para él concebida como época clásica), se originaban en la consideración del lenguaje que reside en la aparente opacidad y clausura de las choses. Según el filósofo francés, el lenguaje de esta época no era aún un sistema arbitrario de signos, sino un conjunto de palabras que se proponía indicar y descifrar las cosas en sí mismas. Por eso precisamente, la lengua, que tenía entonces una relación directa de analogía con el mundo que representaba, podía ser estudiada también como una realidad en cierto modo natural. El encadenamiento de unas palabras con otras, mediante las oportunas reglas de la sintaxis, guardaba relación de igual manera con la disposición que podían tener las cosas como elementos de orden del mundo real ${ }^{7}$.

Los desarrollos conceptuales de Michel Foucault llevaron pocos años después a plantear una arqueología de los saberes, tomando como base las positividades a partir de las cuales se generaban los conocimientos o se ofrecían como concreción de los conocimientos mismos. En la Arqueología del saber, cuya primera edición francesa data de 1969 (solo tres años después de Las palabras y las cosas), el autor buscaba fundamentar el origen de las formaciones discursivas en las materialidades (objetos, textos, técnicas...), a las que atribuía el valor de documentos y con las que se podían construir archivos. La arqueología que él sugiere no es la de los monumentos mudos, los rastros inertes o los objetos sin contexto, sino una disciplina intelectual que problematiza históricamente las series de cosas, las relaciones entre estas, las continuidades y discontinuidades en su generación y sus usos, y los procesos de emergencia, apropiación y transferencia intercultural de los objetos. El nuevo arqueólogo, a partir de las denominadas "experiencias prediscursivas", que encontraba o formulaba en sus contactos directos con la realidad, se iría no obstante liberando de las cosas, en su consideración de simples objetos, para ir accediendo al descubrimiento de las reglas que permitían extraer y

\footnotetext{
${ }^{6}$ Freeman Tilden, La interpretación de nuestro patrimonio, Sevilla, Asociación para la Interpretación del Patrimonio, 2006, p. 19-10 y 37.

${ }^{7}$ Michel Foucault, Las palabras y las cosas, México, Siglo XXI, 1968, p. 42-46.
} 
formular los materiales, que son las que en definitiva facilitarían el acceso al orden del discurso buscado $^{8}$.

Siguiendo ideas afines a este giro fenomenológico, el ámbito de lo material se ha hecho cada vez más presente en la investigación histórica acerca de las instituciones de formación entre las últimas generaciones de historiadores. La operación historiográfica se cobija hoy en los nichos ecológicos que ofrecen al analista del pasado los objetos y las representaciones, testimonios que hacen visibles los hechos educativos. Son pocas las monografías u obras sistemáticas acerca de la historia de las instituciones educativas que no insertan entre los textos, o anexan en sus apéndices, imágenes sobre las escuelas, los contextos, los actores, los instrumentos u otros elementos materiales vinculados a lo que fue en un tiempo determinado el cotidiano transcurrir de la vida escolar o a las experiencias educativas que se llevaron a cabo entre los muros de las aulas o fuera de ellos. A estos trabajos suelen asimismo añadirse inventarios, más o menos analíticos, de las dotaciones materiales de los establecimientos docentes, de los registros de trabajo de los sujetos y del equipamiento ergológico de los enseñantes. Hay que convenir, empero, como ya se ha advertido, que a este trabajo de inventario y registro de las cosas no ha acompañado siempre una hermenéutica de la cultura que en ellas se encripta. Digamos que los historiadores, ensayando a veces a ejercer la sensibilidad de los anticuarios, han estado demasiado apegados a las materialidades, sin liberarse de ellas y hasta constituyéndolas en fetiches de seducción, juego y colección. En la perspectiva foucaultiana, la investigación debería orientarse sin embargo hacia un cierto desprendimiento respecto de lo matérico observable y manipulable y aventurarse a emprender, por la vía de la semántica y de la hermenéutica, la interpretación de los significados que se ocultan tras las cosas, los hechos y las manifestaciones en que se muestran en contextos reales.

El giro anterior sí ha propiciado, pese a sus señaladas limitaciones, el avance hacia la acreditación de la historia material. En las últimas décadas se ha instalado entre los historiadores la creencia de que los testimonios materiales, o sus representaciones, al mostrarse como positividades observables y como fuentes factuales de la realidad estudiada, son inequívocamente más fiables que otras referencias para ofrecer una prueba empírica de lo que los procesos educativos han sido en el pasado, e incluso de lo que actualmente son. Las cosas, además operan igualmente en el cotidiano que vivimos, en el contexto del llamado tiempo presente, un tiempo que por lo demás aún ofrece, junto a las innovaciones propias de la época actual, diversas manifestaciones que son prueba de las persistencias de la tradición en las

\footnotetext{
${ }^{8}$ Michel Foucault, La arqueología del saber, México, Siglo XXI, 1970, p. 78-79.
} 
escuelas de hoy, unas como signos de obsolescencia y otras como mediaciones instrumentales todavía acreditadas y de más larga vigencia.

\section{POR UNA MIRADA MÁS REALISTA Y SINCERA DEL PASADO}

El viraje hacia la estimación de los hechos observables se operó tras haber cuestionado la nueva historia la legitimidad, dominante en las décadas anteriores, de los análisis teóricos y políticos con que se examinó e interpretó el mundo pedagógico. La crítica de la modernidad problematizó el valor de los discursos tradicionales, e incluso de los modernos, en los que se sustentaba la vieja historia, y puso bajo sospecha las intenciones y los intereses que subyacían en ella. Indujo a este respecto no solo un giro fenomenológico hacia las positividades sino la deconstrucción crítica de aquellos discursos implícitos en los hechos que se examinaban, en busca de un análisis más realista y más sincero del mundo de la educación y de los entornos que la han condicionado en el pasado. Ello favoreció la emergencia de nuevas miradas hacia la escuela y hacia la formación en general, que se orientaron hacia el campo de las experiencias, más primarias o elementales tal vez que los conceptos y los idearios, aunque sin duda menos contaminadas de prejuicios idealistas y supuestos políticos que los aparatos especulativos y de poder e influencia. El desafío derivó entonces hacia la posibilidad de poder leer, comprender e interpretar el mundo de las cosas, o sea, hacia el proyecto intelectual y cultural de desenmascarar los silencios. Para ir en busca de la historia de la experiencia había que dar al traste, entre otras muchas cosas, con el "inútil torneo de las ideas", al que se había referido en sus "combates" por la nueva historia Lucien Febvre ${ }^{9}$. Comprender solo las ideas podía llevar a complicar o a simplificar la inteligencia de los procesos históricos y a ocultar el mundo de la experiencia social, que era el que en verdad debía interesar a los historiadores que entraban a formar parte de la nueva generación de los Annales.

\section{LO MATÉRICO, MEDIACIÓN NECESARIA}

No es nuevo este proyecto intelectual de construir una historia material de las culturas. El llamado materialismo histórico ya había llamado la atención con anterioridad acerca de la importancia de lo material en la construcción de las explicaciones que intervenían en la

\footnotetext{
${ }^{9}$ Lucien Febvre, Combates por la historia, Esplugas de Llobregat, Ariel, 1982, p. 115-116. Original francés de 1952.
}

Rev. Iberoam. Patrim. Histórico-Educativo, Campinas (SP), v. 6, p. 1-19, e020023, 2020. 
dialéctica histórica, no solo como factor determinante del juego que operaba en las relaciones de producción económica, sino por el influjo en la conformación de todo el conjunto de la civilización, estructuralmente afectada por estos cambios técnicos y factuales. El filósofo español Gustavo Bueno dio a luz en 1972 sus Ensayos materialistas, una obra marcada por el marxismo pero al tiempo nacida de una episteme construida con libertad intelectual, en la que el autor renunciaba a la lógica axiomática y se abría al estudio de la realidad como materialidad compleja entretejida bajo el modelo de la simploké, una categoría del pensamiento clásico de la que Bueno se servía para analizar intelectualmente la "complexión" de lo material y las relaciones sistémicas con lo cultural ${ }^{10}$.

Las transformaciones en la tecnología, más allá de su poder innovador en lo instrumental y en lo económico, han comportado importantes y significativos cambios culturales. Los clásicos del marxismo entendieron que el contacto con lo matérico era, además de una acción estratégica de desalienación de los sujetos, una experiencia de un valor formativo primordial, y que las interacciones de los individuos con los objetos físicos que formaban parte del mundo de la vida y del orden productivo deberían ser siempre el comienzo y la base de legitimación de toda pedagogía crítica y emancipadora. John Desmond Bernal construyó, en esta línea discursiva, una historia social de la ciencia, considerando a esta y a su derivada, la tecnología, como una fuerza de producción y liberación. Y la llamada por Radovan Richta revolución científico-técnica — un constructo de gran éxito en los escritos de los años setenta- se sustentaba en definitiva en la puesta en valor, en tanto que fuerza económico-productiva y de cambio cultural, del conocimiento y de la tecnología ${ }^{11}$.

El positivismo valoró igualmente todo lo tecnológico, pero más bien como tekhne, es decir, como elemento de mediación instrumental y formativa o, en todo caso, como performance resultante de la educación académica y profesional de los sujetos, y no necesariamente como variable educativa en sí o como componente esencial con valor ontológico de la evolución sociocultural, salvo en las ideologías asociadas a la idea de progreso que acompañaron a las revoluciones liberal-burguesas y a la industrial ${ }^{12}$. En un ensayo nuestro publicado hace ya algunos años propusimos un argumentario en favor de la consideración de la tecnología y sus ingredientes materiales como una de las humanidades necesarias del currículum del hombre moderno, una innovación pedagógica que corregiría el sesgo de la

\footnotetext{
${ }^{10}$ Gustavo Bueno, Ensayos materialistas, Madrid, Taurus, 1972.

11 Véanse: John D. Bernal, Historia social de la ciencia, Barcelona, Península, 1967, y Radovan Richta, La civilización en la encrucijada, México, Siglo XXI, 1971.

12 Véanse: Daniel Bell, El advenimiento de la sociedad post-industrial, Madrid, Alianza, 1976, y Las contradicciones culturales del capitalismo, Madrid, Alianza, 1977.
} 
tradicional orientación de los programas humanísticos al ámbito de lo especulativo y de lo literario. ¿Hay en verdad algo que sea más humanizador que lo que el hombre hace con sus manos para sobrevivir a los desafíos del medio en que vive y para guiar la evolución colectiva de la especie? ${ }^{13}$.

Eudald Carbonell, paleontólogo de reconocido prestigio, propone entender la evolución de la especie bajo supuestos vinculados a la difusión de la tecnología, sustentando una interpretación cercana a la historia material de la civilización. Los avances de la evolución son, más que progresos biológicamente determinados, un resultado de la socialización de los hallazgos técnicos, que han de ser valorados como logros de cultura. El fuego, de no haber sido socializado, habría que haberlo inventado en las ocasiones en que se hiciera necesario. Los nuevos modos de fecundación in vitro, avances tecnocientíficos, y culturales, han hecho posible que entren en el pool de la evolución dotaciones genéticas de sujetos que no habrían tenido existencia en otras etapas sucesivas de la historia de no haberse producido estos logros biomédicos. En ambos casos, la tecnología material ha afectado a la civilización y a la misma evolución de la especie. La escuela ha sido una agencia de socialización de los logros técnicos y materiales. La reunión de los miembros de la tribu en torno al fuego promovió el lenguaje, el arte y el mito, y creó probablemente la primera escuela en la historia de la humanidad. Y la difusión de los conocimientos acerca de la inseminación también ha sido llevada a cabo en los institutos de investigación y enseñanza. En consecuencia, habría que concluir que la técnica no es solo un recurso instrumental de los sistemas de vida sino un ingrediente esencial de la cultura y de la marcha de la evolución ${ }^{14}$.

Antonio Santoni denunció, en un trabajo que no pasó desapercibido para quienes nos dedicábamos a la historia educativa, la vieja escisión formativa existente entre el brazo y la mente, una bipolaridad de claras implicaciones antropológicas, y no solo formativas. Todo un milenio de educación escindida ha dominado históricamente la educación occidental. Uno de los patrones de esta bipolaridad se basó en el aprender haciendo con las manos e inspiró el modelo del artesanado; el otro se desarrolló siguiendo pautas formales e intelectualistas. Aunque clásicos como Comenio o Pestalozzi - también los enciclopedistas - pusieron en valor la intuición y el contacto con las cosas de la naturaleza y de las artes, así como la ciencia y la tecnología, la práctica escolar quedó anclada en los viejos condicionamientos que han venido

\footnotetext{
${ }^{13}$ Agustín Escolano Benito, "Sobre la acreditación curricular de la tecnología", en La acreditación de saberes y competencias. Perspectiva histórica, XI Coloquio Nacional de Historia de la Educación, Oviedo, Universidad de Oviedo, 2001, p. 130-140.

${ }^{14}$ Eudald Carbonell, El nacimiento de una nueva conciencia, Badalona, Ars Llivres, 2007, p. 120 ss.
} 
operando en la estructura social, que ha seguido marcando la diferencia y ha reforzado la vieja ruptura entre el brazo y la mente ${ }^{15}$.

Continuando con la misma preocupación, Antonio Santoni observó en otro trabajo la emergencia en nuestra sociedad industrial de una cierta nostalgia del maestro artesano, una imagen inexcusablemente asociada a la historia material de la educación. El autor quería suscitar en el medio académico de nuestra época un cierto revival, no nostálgico sino aggiornato, que fundara un nuevo discurso sociohistórico y una nueva acción, en orden a encontrar un modelo formativo integrado. Ello conduciría a la vez a la puesta en valor de la cultura material como fuente de conocimiento histórico. La herencia recibida del artesanado podía incluir también la del oficio de maestro, en cuyo caso los viejos y nuevos objetos didácticos — los que interesan a la historia material de la escuela — serían testimonios empíricos de valor cultural ${ }^{16}$. Tanto las pedagogías ordinarias como las avanzadas, desde Froebel a la Bauhaus, o desde Montessori a Dewey, nos han dejado modelos empíricos que son expresión real y simbólica de una cultura educativa que pone en su centro intelectual y pragmático la experiencia y el trato con las materialidades ${ }^{17}$. Las pedagogías no encarnadas en la experiencia quedarían marginadas como discursos idealistas abocados a lo abstruso. En consecuencia con lo anterior, los legados materiales conservados son fieles y necesarios testigos de los sistemas pedagógicos que implementaron.

En años más próximos a nosotros, la sociología de la cultura de Richard Sennett ha vuelto a subrayar la idea-fuerza de que en toda acción humana opera siempre algún tipo de relación con lo material. La corrosión del carácter de los sujetos en la civilización industrial que daba título a uno de los análisis más sugerentes de Sennett- derivaba de las fragmentaciones laborales operadas por la economía del capitalismo. Estas divisiones del trabajo habrían roto con las rutinas técnicas y con los rituales que relacionaban armónicamente a los sujetos productores con las cosas materiales y con los otros. Somos en parte lo que hacemos con los objetos materiales y junto a las personas que cooperan en su diseño y ejecución.

El cambio en los modos de producción, que se opera con las innovaciones en las tecnologías y en la dinámica de los procesos del nuevo industrialismo, ha dado pie a mudanzas en las identidades profesionales e incluso morales. Richard Sennett comenta, a estos efectos,

\footnotetext{
${ }_{15}$ Antonio Santoni Rugiu, Il braccio e la mente. Un millennio di educazione divaricata, Firenze, La Nuova Italia, 1995, p. 261.

${ }^{16}$ Antonio Santoni, Nostalgia del maestro artesano, México, UNAM-CESU, 1996.

${ }^{17}$ Véase la introducción a la obra anterior, p. 51 ss.
} 
experiencias que él había observado en el ámbito innovador de las nuevas tecnologías de IBM y en otro sector más tradicional, el de la industria de la panificación. En base a estas observaciones, el sociólogo norteamericano analiza las reacciones de los trabajadores y las transformaciones que se operaron en su personalidad, así como en el mismo ethos personal y corporativo de los profesionales del sector estudiado ${ }^{18}$. Lo material, en la dimensión tecnológica, era un determinante de la cultura del trabajo y de los comportamientos sociomorales de los individuos adscritos al grupo social de referencia, un ingrediente esencial y necesario en el que poder sustentar una antropología y una determinada forma de civilización.

En sus obras más recientes, El artesano y Juntos, Richard Sennett muestra de forma empírica como en cualquier actividad, desde las relacionadas con la expresión corporal a las propiamente cognitivas o intelectuales, opera algún hecho material. Ello es expresión no solo del valor instrumental de la tecnología sino del carácter cultural que tienen las materialidades y las experiencias factuales a que se vinculan estas ${ }^{19}$. Más aún, aunque las creaciones materiales puedan ser el resultado del ingenio personal, su incardinación en la realidad suele requerir la cooperación de varios individuos e incluso de colectivos que funcionan siguiendo pautas de solidaridad que dan origen a modos específicos de socialización, que son a la vez formas culturales. Construir y montar una escalera de varios tramos — uno de los ejemplos de los que se sirve Sennett para ilustrar esta cuestión — implica actividades coordinadas entre los diversos operarios que intervienen en la tarea, quienes aplican sus habilidades y destrezas personales al montaje in situ de un dispositivo prácticamente universal en las construcciones destinadas a habitación, sirviéndose en ello de acciones perceptivas y motoras que dan como resultado final la obra esperada ${ }^{20}$.

\section{HISTORIA MATERIAL, HISTORIA EFECTUAL}

No es nuevo, por tanto, el reclamo de lo material como elemento constitutivo de los modos efectivos que regulan los sistemas de socialización cultural. También sucede así en la configuración de las prácticas en que se materializa la cultura empírica de la escuela. Por ello justamente, ahora, la nueva historiografía, más etnográfica que la tradicional, quiere buscar en los restos arqueológicos que nos han quedado de las antiguas y modernas instituciones

\footnotetext{
${ }^{18}$ Richard Sennett, La corrosión del carácter. Las consecuencias personales del trabajo en el nuevo capitalismo, Barcelona, Anagrama, 2006 (original de 1998).

${ }^{19}$ Richard Sennett, El artesano, Barcelona, Anagrama, 2009, p. 20.

${ }^{20}$ Richard Sennett, Juntos. Rituales, placeres y política de cooperación, Barcelona, Anagrama, 2012, imagen de cubierta.
} 
educativas las bases materiales que permitan explicar e interpretar los modelos de formación. Descodificando los legados recibidos, leyendo los signos adheridos a la misma fisicalidad de los objetos y de las representaciones, los analistas esperan acercarse a descifrar algunos de los códigos de la supuesta gramática de la escuela de la que hablan determinados historiadores, o sea, las claves que han regulado su pragmática y su cultura efectual.

En las anteriores huellas se enraizarían además las funciones que han llegado a definir históricamente el habitus de los enseñantes, que afectarían a la tecnología y a su ethos corporativo, al igual que ha ocurrido en otros oficios. En esta tekhne radicaría su arte profesional, un tipo de sabiduría experiencial que se ha venido originando y sedimentando en gran medida en la misma práctica, manejando los elementos que la propia corporación docente en parte ha inventado, acreditado y difundido a lo largo del tiempo en el ámbito de trabajo. Con ello se está afirmando a la vez que esta cultura de la acción nos viene siempre dada cargada de historicidad, de tal suerte que los objetos en que se materializó habrían ido transformándose con el tiempo a partir de un patrón inicial que se mostraría como invariante pero que adoptaría asimismo variaciones culturales. La intervención a posteriori del historiador de la educación consistiría en desvelar en las huellas impresas en las materialidades los caracteres del modelo de cultura implícita que encierran y los cambios inducidos por el devenir histórico.

La operación es atractiva, ambiciosa y de resultado incierto, y probablemente no siempre satisfactorio, al menos de modo suficiente. En una recensión que Raimundo Cuesta hizo en su día de la Historia ilustrada de la escuela en España, una obra que publicamos en $2006^{21}$, se hablaba de la "endoscopia" que aquel trabajo llevaba a cabo en torno a la escuela ${ }^{22}$. Esta metáfora me pareció acertada entonces toda vez que, en efecto, las imágenes que ilustraban el texto de referencia podían permitir una lectura verboicónica transversal del pasado escolar, un descifrado que se hacía en clave etnográfica, a partir del acercamiento a las fuentes objetuales por medio de un supuesto visor endoscópico que las diseccionaba y analizaba. Se acercaba asimismo a ensayar una explicación de los modos empíricos de educación que subyacían en aquellos registros y en las representaciones. Ello no eximía de la necesidad de buscar una interpretación más compleja del conjunto de las materialidades examinadas en el contexto de las formaciones sociohistóricas en que estos iconos y objetos se inventaron y utilizaron. La conclusión era obvia: la historia material podía ser necesaria aunque no era suficiente, y había de ser en todo caso integrada en el marco interpretativo de una historia social

\footnotetext{
${ }^{21}$ Agustín Escolano Benito (dir.), Historia ilustrada de la escuela en España. Dos siglos de perspectiva histórica, Madrid, Fundación Germán Sánchez Ruipérez, 2006.

${ }^{22}$ Raimundo Cuesta, "Endoscopia a la escuela en España", Con-Ciencia Social, 11, 2007, p. 119-124.
} 
y cultural más amplia y compleja. Pero al mismo tiempo había que asumir que la historia sociocultural tampoco podía llevarse a cabo sin contar con las materialidades.

También resultaba evidente que los materiales eran producto de un proceso histórico de creación y circulación, y los cambios en las tecnologías de gestión de la enseñanza y el aprendizaje en la escuela podían promover transformaciones en la sociedad y en la civilización, con lo que la institución educativa misma adquiría el estatus de fuerza productiva, sobre todo cuando sus acciones, condicionadas por las materialidades, determinaban la formación de los sujetos en amplias masas de la ciudadanía y a través de tiempos largos de escolarización, hecho constatable en todas las sociedades ilustradas.

La nueva perspectiva historiográfica abocaba pues a buscar el acceso a la historia escolar a través de los testimonios materiales, un acceso que por lo demás había de ser necesariamente contextualizado. En las fuentes tangibles podría haber quedado encriptada la realidad y la cultura educativa de un momento histórico a analizar, aunque desde una orientación más compleja que la derivada de un enfoque meramente etnográfico-descriptivo. La etnohistoria debería intentar construir una nueva cultura de la educación que se sustentara en el contexto epistémico de una historia de la experiencia, en la que lo material se constituía como un contenido esencial de la empeiria, si bien esta referencia a la realidad no constituyese el único criterio de verdad. Para ello había que mostrar que los datos físicos del patrimonio histórico-educativo no eran solo una prueba de valor instrumental sino el testimonio en el que poder descifrar las señales que dan razón de la cultura empírica de la escuela, la que se supone habría quedado plasmada en los objetos y en las representaciones, que serían signos de lo que Zigmunt Bauman definiría al hablar de la cultura como práctica. Esto implicaba a la vez legitimar la práctica como cultura ${ }^{23}$.

Las cosas, en resumen, no son materialidades banales, fungibles y efímeras, sino textos a leer e interpretar. Para Borges guardan secretos importantes de la historia de la experiencia humana y trascienden la relación con los sujetos que las crearon y con los primeros usuarios. Tienen por tanto un claro interés historiográfico y antropológico. Foucault situó la relación con las cosas en el núcleo mismo de las por él llamadas experiencias prediscursivas, antes aludidas, como primer umbral de la fenomenología y de una arqueología del saber. El materialismo dialéctico vio en las materialidades una mediación emancipadora y una fuerza que determinaba los modos de producción. La nueva sociología de la cultura ha venido a subrayar la presencia de lo empírico y lo matérico en todo tipo de construcción intelectual y en las correspondientes

\footnotetext{
${ }^{23}$ Zigmunt Bauman, La cultura como praxis, Barcelona, Paidós, 2002, p. 14.
} 
formas de sociabilidad que acompañan a los procesos de creación y comunicación. Las cosas no son por tanto objetos que puedan ser desligados de los discursos y de los patrones sociales que conforman la cultura. En el caso de la educación, los objetos materiales y sus representaciones son testimonios que hablan de las culturas pedagógicas, así como de los sujetos implícitos que se han formado en ellas. La lectura de estas cosas materiales se constituye así en un imperativo hermenéutico para la comprensión de la historia de la escuela y de la formación en general.

\section{REFERÊNCIAS}

BAUMAN, Zigmunt. La cultura como praxis. Barcelona: Paidós, 2002, p. 14.

BELL, Daniel. El advenimiento de la sociedad post-industrial. Madrid: Alianza, 1976,

BELL, Daniel. Las contradicciones culturales del capitalismo. Madrid: Alianza, 1977.

BERNAL, John D. Historia social de la ciencia, Barcelona. Península: 1967.

BUENO, Gustavo. Ensayos materialistas. Madrid: Taurus, 1972.

CARBONELL, Eudald. El nacimiento de una nueva conciencia. Badalona: Ars Llivres, 2007, p. 120 ss.

CUESTA, Raimundo. "Endoscopia a la escuela en España”. Con-Ciencia Social, 11, 2007, p. 119-124.

ESCOLANO BENITO, Agustín, "Sobre la acreditación curricular de la tecnología", en: La acreditación de saberes y competencias. Perspectiva histórica, XI Coloquio Nacional de Historia de la Educación, Oviedo, Universidad de Oviedo, 2001, p. 130-140.

ESCOLANO BENITO, Agustín (dir.), Historia ilustrada de la escuela en España. Dos siglos de perspectiva histórica. Madrid: Fundación Germán Sánchez Ruipérez, 2006.

ESCOLANO BENITO, Agustín (ed.). La cultura material de la escuela. Berlanga de Duero: CEINCE, 2007.

ESCOLANO BENITO, Agustín. La cultura empírica della scuolo. Esperienza, memoria, archeologia. Ferrara: Ed. Volta la Carta, 2016.

FEBVRE, Lucien, Combates por la historia. Esplugas de Llobregat: Ariel, 1982, p. 115116. Original francés de 1952.

FOUCAULT, Michel. Las palabras y las cosas. México: Siglo XXI, 1968, p. 42-46.

FOUCAULT, Michel. La arqueología del saber. México: Siglo XXI, 1970, p. 78-79. 
LYONS, Martyn. Historia de la lectura y de la escritura en el mundo occidental. Buenos Aires: Editoras del Calderón, 2012, p. 51-53.

MARCOS, Alfredo. El testamento de Aristóteles: memorias desde el exilio, León: Editorial Edilesa, 2000, p. 123-124.

RICHTA, Radovan. La civilización en la encrucijada. México: Siglo XXI, 1971.

SANTONI RUGIU, Antonio. Il braccio e la mente: un millennio di educazione divaricata. Firenze: La Nuova Italia, 1995, p. 261.

SANTONI RUGIU, Antonio. Nostalgia del maestro artesano. México: UNAM-CESU, 1996.

SENNETT, Richard. La corrosión del carácter: las consecuencias personales del trabajo en el nuevo capitalismo. Barcelona: Anagrama, 2006 (original de 1998).

SENNETT, Richard. El artesano. Barcelona: Anagrama, 2009, p. 20.

SENNETT, Richard. Juntos: rituales, placeres y política de cooperación. Barcelona: Anagrama, 2012, imagen de cubierta.

TILDEN, Freeman. La interpretación de nuestro patrimonio. Sevilla: Asociación para la Interpretación del Patrimonio, 2006, p. 19-10 y 37.

Recebido em: 08 de dezembro de 2020 Aceito em: 14 de dezembro de 2020 